UNIVERSIDADE DE SÃO PAULO - USP

FACULDADE DE ECONOMIA, ADMINISTRAÇÃO E CONTABILIDADE

DEPARTAMENTO DE ECONOMIA

PROGRAMA DE PÓS-GRADUAÇÃO EM ECONOMIA

\title{
Optimal Road Network and The Gains from Intranational Trade
}

\author{
Lucas Cardoso Corrêa Dias
}

Orientador: Eduardo Amaral Haddad

São Paulo

2020 
Prof. Dr. Vahan Agopyan

Reitor da Universidade de São Paulo

Prof. Dr. Fábio Frezatti

Diretor da Faculdade de Economia, Administração e Contabilidade

Prof. Dr. Jose Carlos de Souza Santos

Chefe do Departamento de Economia

Prof. Dr. Ariaster Baumgratz Chimeli

Coordenador do Programa de Pós-Graduação em Economia 


\title{
Optimal Road Network and The Gains from Intranational Trade
}

\begin{abstract}
Dissertação apresentada ao Departamento de Economia da Faculdade de Economia, Administração e Contabilidade da Universidade de São Paulo como requisito parcial para a obtenção do título de Mestre em Ciências.
\end{abstract}

Orientador: Eduardo Amaral Haddad

Versão Original

São Paulo

2020 
Dias, Lucas.

Optimal Road Network and The Gains from Intranational Trade / Lucas Dias. - São Paulo, 2020. $60 \mathrm{p}$.

Dissertação (Mestrado) - Universidade de São Paulo, 2020. Orientador: Eduardo Amaral Haddad .

1. Comércio Intranacional. 2. Economia Espacial. 3. Redes Ótimas de Transporte. 4. Experimento Brasília. I. Universidade de São Paulo.

Faculdade de Economia, Administração e Contabilidade. II. Título. 
Lucas Cardoso Corrêa Dias

\section{Optimal Road Network and The Gains from Intranational Trade}

Dissertação apresentada ao Departamento de Economia da Faculdade de Economia, Administração e Contabilidade da Universidade de São Paulo como requisito parcial para a obtenção do título de Mestre em Ciências.

Eduardo Amaral Haddad

Orientador

Andrés Jorge Maggi

Carlos Roberto Azzoni

Joao Paulo Cordeiro de Noronha

Pessoa

São Paulo

2020 



\section{Acknowledgements}

First, I would like to thank my family for all the support.

I am very grateful to my advisor, Eduardo Haddad, for all the trust placed in me and for the guidance throughout the process. I also thank Andrés Maggi for kindly accept help me in this work, through advice and fruitful discussions that improved this paper.

I am also indebted to all my friends from USP. I learned a lot from talking to so many brilliant, diverse, and kind people. Every hard moment was softer and somewhat fun because of them. I am sure I made not only brilliant professional colleagues but, especially, good friends in these two years.

I would also like to thank Gabriela. Thanks for everything during these years.

Finally, this study was financed in part by the Fundação Instituto de Pesquisas Econômicas (FIPE) and by the Conselho Nacional de Desenvolvimento Científico e Tecnológico $(\mathrm{CNPq})$. For their financial support, I thank both institutions. 



\section{Abstract}

I study the efficiency of the Brazilian road network and its welfare implications combining rich spatial data on roads and a spatial general equilibrium model calibrated to 557 Brazilian regions. I find that Brazil would gain $0.31 \%$ of welfare if better organize its current road network to promote internal trade. At the subnational level, the least developed regions in the country's north and northeast would be the most benefited ones from a hypothetical optimal reallocation scenario. I then use the construction of a new federal capital city in the last century in a quasi-experimental setting and find that a large-scale infrastructure project does influence the current spatial misallocation patterns in the Brazilian road network.

Key words: Intranational Trade, Spatial Economics, Optimal Transport Networks, Brasília Experiment. 



\section{Resumo}

Eu estudo a eficiência da rede rodoviária brasileira e suas consequências em termos de bem-estar utilizando dados de rodovias e um modelo de equilíbrio geral espacial calibrado para 557 regiões brasileiras. Eu encontro que o Brasil ganharia 0.31\% de bem-estar se organizasse melhor sua atual rede de rodoviária para promover comércio interno. A nível subnacional, as regiões menos desenvolvidas no norte e nordeste do país seriam as mais beneficiadas do cenário hipotético de realocação ótima. Eu então uso a construção da nova capital nacional em meados do século passado em um contexto quasi-experimental e encontro que projetos de infraestrutura de larga escala influenciam o atual padrão de misallocation espacial na rede rodoviária brasileira.

Palavras-chave: Comércio Intranacional, Economia Espacial, Redes Ótimas de Transporte, Experimento Brasília. 



\section{Contents}

$1 \quad$ INTRODUCTION $\ldots \ldots \ldots \ldots \ldots \ldots$

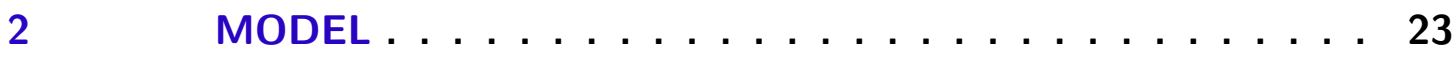

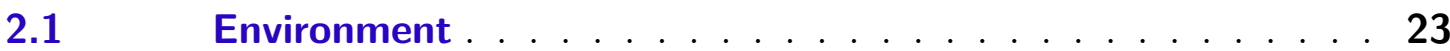

$2.2 \quad$ Planner's Problem . . . . . . . . . . . . . . . . 25

3 DATA AND CALIBRATION $\ldots \ldots \ldots \ldots \ldots$

4 GAINS FROM OPTIMAL REALLOCATION . . . . . 31

5 BRASÍLIA AND THE SPATIAL MISALLOCATION OF ROADS 41

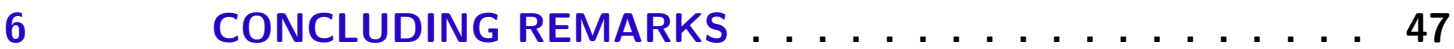

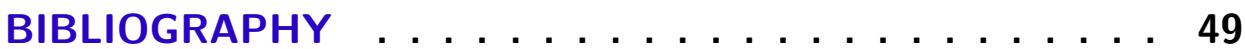

$\begin{array}{ll}\text { APPENDIX } & 51\end{array}$

APPENDIX A - HIERARCHY . . . . . . . . . 53

APPENDIX B - NUMERICAL SOLUTION . . . . . . 55

APPENDIX C - ADDITIONAL FIGURES . . . . . . 59 



\section{List of Figures}

Figure 1 - Brazilian road network . . . . . . . . . . . . . . 32

Figure 2 - Discretized network . . . . . . . . . . . . . 33

Figure 3 - Optimal road network . . . . . . . . . . . 35

Figure 4 - Welfare and Infrastructure changes . . . . . . . . . . . . 36

Figure 5 - Spatial distribution of welfare gains - microregions . . . . . . . 38

Figure 6 - Spatial distribution of welfare gains - states . . . . . . . . . . 39

Figure 7 - Radial Highways and Euclidean Minimum Spanning Tree . . . . 43

Figure 8 - Hierarchy - Municipalities . . . . . . . . . . . . . 54

Figure 9 - Hierarchy - Microregions . . . . . . . . . . . . . . 54

Figure 10 - Kernel Density: Observed Average Speeds . . . . . . . . . . . . 59

Figure 11 - Histogram: Relative Welfare Gains . . . . . . . . . . . . . 60 



\section{List of Tables}

Table 1 - Regions and sectors . . . . . . . . . . . . . . . . . 29

Table 2 - Effects of the Radial Highways: extensive margin . . . . . . . . . 45

Table 3 - Effects of the Radial Highways: intensive margin . . . . . . . . . 46

Table 4 - REGIC's hierarchy levels . . . . . . . . . . . . . . 53 



\section{Introduction}

Trade costs are essential determinants of trade flows, regional specialization, and the welfare gains from trade. Consequently, there is a vast literature concerned with their causes. Anderson and Wincoop (2004) show that the determinants of trade costs are numerous and range from geographical characteristics such as distance and physical barriers, to political economy features like trade agreements. A large number of quantitative trade models have been used to estimate the consequences of international trade costs, but there is much less evidence about the consequences of intranational trade $\operatorname{costs}^{1}$.

In a subnational setting, the majority of the determinants of trade costs disappear, and geography, through transport costs, becomes one of their main drivers. Internal transport costs are even more critical issues in large countries, where trade across regions tend to be greater than with other countries (MAGGI, 2019). Policymakers and international organizations recognize the central importance of transport costs. Emerging economies spend up to $10 \%$ of their budget in transport infrastructure (FELBERMAYR; TARASOV, 2015) and between 2000 and 2010 the World Bank allocated more than US\$56 billions to road construction and maintenance (COLLIER; KIRCHBERGER; SöDERBOM, 2016).

Together, these aspects suggest Brazil as a prominent case study. Brazil is the largest country in Latin America and its internal trade is more than three times larger than its international trade (MAGGI, 2019). Transport costs are well recognized as one of the causes of low competitiveness in the Brazilian economy. As Maggi and Haddad (2016) argue, the logistic costs account for more than $15 \%$ of GNP in Brazil, higher than the equivalent share for other emerging economies. Both federal and state governments recently planned large-scale infrastructure projects to overcome Brazilian dependency on roads and its lack of proper transport infrastructure. It is widely known that Brazil needs more transport infrastructure, but

$\overline{1}$ See Costinot and Rodríguez-Clare (2014) for a comprehensive review of the quantitative trade models. 
much less is known about how well allocated the current infrastructure investments are in Brazil.

This paper aims to answer two main questions, namely: How well organized is the current infrastructure network in Brazilian regions? What can explain the spatial pattern of infrastructure misallocation? To address the first question I follow Fajgelbaum and Schaal (2017) and use a spatial general equilibrium model that features costly trade, realistic geography, congestion externality, and urban hierarchy. In the model, regions are organized in a graph and connected by the transport infrastructure and there is a social planner who chooses which edge to improve and how much to invest in it.

I calibrate the model to 557 Brazilian microregions using rich spatial data on roads and analyze the counterfactual scenario in which the social planner can reorganize the current road infrastructure to promote internal trade. I then use the model results in a quasi-experimental setting provided by the creation of a new capital city and its related highway system in Brazil to test if a large-scale infrastructure project that occurred in the last century can influence the current misallocation patterns. This exercise sheds light on my second question.

The main results indicate that the optimal reallocation would lead to a welfare gain of $0.31 \%$ in national terms, with important regional heterogeneity. The highest welfare-improving connections are located in the poorer and remote regions within the country, which benefit the most from the hypothetical reallocation of roads. This pattern of spatial reallocation, namely, benefiting the least developed regions at the expense of the wealthier in relative terms, reveals the relative supply of road infrastructure across the country. I use these results with data on Brazilian roads to investigate if the highway system built to integrate Brasília with the rest of the country - called Brasília's Radial Highways - influenced the spatial misallocation of road infrastructure. I deal with the endogeneity of route choice using a least-cost path network and find that regions connected by these highways are relatively oversupplied of transport infrastructure even passed more than 50 years. This result is robust to different specifications and is qualitatively the same both at the intensive and extensive margins. 
This paper contributes to several strands of literature. It firstly relates to the recent efforts to consider endogenous trade costs. Within this literature there are two main approaches to incorporate endogenous trade costs. The first one introduces a decentralized market for transport as in Asturias (2020), with a transport industry that features oligopolistc competition, and Brancaccio, Kalouptsidi and Papageorgiou (2020), through a matching process between ships and exporters. The second approach, which this paper mostly relates to, considers a given transport technology and a government or social planner which chooses the set of infrastructure investments - hence trade costs - to maximize aggregate welfare. In Santamaria (2020)'s model, for instance, the government chooses the infrastructure levels facing the market allocation as a constraint - in a Stackelberg-like game. I rather follow the approach presented in Fajgelbaum and Schaal (2017), where a social planner chooses the infrastructure allocations in a full optimization problem that encompasses the whole set of allocations of the economy. The model I use is a specific version of the theoretical framework developed by them.

In a closely related paper, Graff (2019) derives the optimal transport networks for each African country and then provides some evidence on the persistent effects of colonial (railroad) infrastructure investments. My work differs from his paper in subtle but important aspects. I calibrate the model using meaningful geographical units rather than grid cells and introduce urban hierarchy levels instead of the urban-rural duality in the case of the African countries. Besides, while Graff (2019) relies on comparisons between built and planned railroads through OLS estimations to infer the effects on infrastructure misallocation, my reduced-form results are based on instrumental variable estimations, which I claim to be causal. In addition, I am using an infrastructure project that exclusively built highways.

My results are also related to the literature that studies the effects of the Brasília's Radial Highways. Bird and Straub (2020) show that the road expansion increased GDP at the municipality level. Morten and Oliveira (2016) find that the highways did promote trade and migration flows. Astorga (2019) still shows that better market access caused by the Radial Highways improved agricultural productivity. I use an identification strategy based on Morten and Oliveira (2016) and Astorga (2019) and find that besides these positive effects, the regions connected 
by the highways are, on average, oversupplied with transport infrastructure relative to the non-connected ones. To the best of my knowledge, this is first evidence on a negative effect associated with this project.

Finally, this paper adds to the literature that use structural models to assess the consequences of major changes in Brazil's internal trade costs. Almeida, Haddad and Hewings (2010) conduct several simulations relative to trade costs within a Brazilian state and evaluate their results through the lens of an equity-efficiency trade-off for transport infrastructure investments. Haddad et al. (2011) assess the likely effects of the improvement of two important Brazilian highways at the substate level. Maggi and Haddad (2016) estimate how large would be the gains from the China shock if Brazil had better transport infrastructure, while Maggi (2019) study the importance of both internal and external integration in a multiregion-country-sector trade model. None of these papers explicitly endogeneize internal trade costs to study their global and local efficiency in terms of spatial misallocation.

The remainder of this paper proceeds as follows: Section 2 details the model environment and planner's problem; Section 3 describes the data and parameters for the calibration of the model - closely linked to the numerical solution, which I present in the Appendix; Section 4 discusses the results for the optimal reallocation of roads; Section 5 investigates the effects of the Brasília's Radial Highways creation on the welfare gains from the counterfactual road allocation; Section 6 concludes with the final comments. 


\section{Model}

This section details the model I use in the counterfactual analysis. The formal structure follows Graff (2019) closely although I introduce some important modifications in the calibration, which I cover in the next section. The model is a version of the spatial general equilibrium framework developed and applied by Fajgelbaum and Schaal (2017).

\subsection{Environment}

Consider a discrete set of regions $\mathscr{I}=\{1, \ldots, I\}$. Each region $i \in \mathscr{I}$ inhabits $L_{i}$ consumers that derives utility from the consumption of tradable goods. Welfare is a concave function of consumption and follows the form:

$$
u_{i}=c_{i}^{\alpha}
$$

where $c_{i}$ denotes the total consumption per capita, so aggregate consumption is $L_{i} c_{i}$, and $\alpha<1$.

There is a set $\mathscr{N}=\{1, \ldots, N\}$ denoting the number of goods in this economy and aggregate consumption in each location is given by a CES function:

$$
L_{i} c_{i}=\left(\sum_{n=1}^{N}\left(C_{i}^{n}\right)^{\frac{\sigma-1}{\sigma}}\right)^{\frac{\sigma}{\sigma-1}}
$$

where $C_{i}^{n}$ is the total consumption of the good $n$ in the region $i$ and $\sigma$ is the elasticity of substitution between goods.

In the supply side of the economy I assume a Ricardian trade model without labor mobility ${ }^{1}$ and that each region only supplies one variety $n \in \mathscr{N}$. The first

$1 \quad$ Fajgelbaum and Schaal (2017) assume a Ricardian economy with linear production technology. They assume that the observed allocation is a solution of the planner's problem with the current network fixed and use this information to back out the productivities. 
assumption does not require any calibration of the production function parameters since the output level remains fixed. So, I can subsume these two hypothesis as:

$$
Y_{i}=Y_{i}^{n}
$$

Each region $i \in \mathscr{I}$ is a node of a connected graph, and can trade with its connected regions $k \in N(i)$. So every good $n \in \mathscr{N}$ can be traded across all the graph's nodes as long as it passes through connected regions. Trade costs follow the standard iceberg hypothesis $\left(1+\tau_{i, k}^{n}\right)$ with the form:

$$
\tau_{i, k}^{n}\left(Q_{i, k}^{n}, I_{i, k}\right)=\delta_{i, k}^{\tau} \frac{\left(Q_{i, k}^{n}\right)^{\beta}}{\left(I_{i, k}\right)^{\gamma}}
$$

where $\tau_{i, k}^{n}$ denotes the good-origin-destination specific trade costs. $\delta_{i, k}^{\tau}$ represents the origin-destination geographic trade cost, $Q_{i, k}^{n}$ is the total flow of good $n$ from $i$ to $k \in N(i)$ and $I_{i, k}$ is the level of transport infrastructure between the regions $i$ and $k \in N(i)$. In this log-linear specification, the parameters $\beta$ and $\gamma$ represent the elasticity of trade costs relative to the flow of goods and the infrastructure investment, respectively. Note that $\beta>0$ implies congestion externality in trade costs and $\gamma>0$ means that infrastructure investments can ease the negative effects of geography.

In this trade network there may be trade of every good $n=1, \ldots, N$ in every region $i=1, \ldots, I$. In equilibrium, each region must produce and import an amount at least as big as it consumes and exports. Formally, the balanced flows imply the following constraint:

$$
C_{i}^{n}+\sum_{k \in \mathscr{N}(i)} Q_{i, k}^{n}\left(1+\tau_{i, k}^{n}\left(Q_{i, k}^{n}, I_{i, k}\right)\right) \leq Y_{i}^{n}+\sum_{j \in \mathscr{N}(i)} Q_{j, i}^{n}
$$

where the right-hand side is total amount of good $n$ produced and imported by region $i$ and the total consumed and exported is in the left-hand side.

Finally, there is an exogenous amount of infrastructure $K$ that can be allocated in the whole network. The cost of building infrastructure also differs 
between origin-destination pairs and is denoted by $\delta_{i, k}^{I}$. Consequently, every change in the infrastructure network is restricted to the following building constraint:

$$
\sum_{i} \sum_{k \in \mathscr{N}(i)} \delta_{i, k}^{I} I_{i, k} \leq K
$$

\subsection{Planner's Problem}

Based on the this framework, I solve the problem of a benevolent social planner who maximizes aggregate welfare choosing the set of total consumption of goods, trade flows and infrastructure investments for the whole network subject to the balanced-flows and network-building constraints stated in equations 2.5 and 2.6, respectively. Assuming that the planner equitably value all consumers, the Planner's Problem can be written as:

$$
\left\{\left\{C_{i}^{n},\left\{Q_{i, k}^{n}\right\}_{k \in N(i)}\right\}_{n}, c_{i},\left\{I_{i, k}\right\}_{k \in N(i)}\right\}_{i}
$$

subject to:

$$
\begin{gathered}
L_{i} c_{i} \leq\left(\sum_{n=1}^{N}\left(C_{i}^{n}\right)^{\frac{\sigma-1}{\sigma}}\right)^{\frac{\sigma}{\sigma-1}} \forall i \in \mathscr{I} \\
C_{i}^{n}+\sum_{k \in \mathscr{N}(i)} Q_{i, k}^{n}\left(1+\tau_{i, k}^{n}\left(Q_{i, k}^{n}, I_{i, k}\right)\right) \leq Y_{i}^{n}+\sum_{j \in \mathscr{N}(i)} Q_{j, i}^{n} \forall i \in \mathscr{I}, n \in N \\
\sum_{i} \sum_{k \in \mathscr{N}(i)} \delta_{i, k}^{I} I_{i, k} \leq K \\
I_{i, k}=I_{k, i} \forall i \in \mathscr{I}, k \in \mathscr{N}(i) \\
C_{i}^{n}, c_{i}, Q_{i, k}^{n} \geq 0 \quad \forall i \in \mathscr{I}, k \in \mathscr{N}(i) \text { e } n \in N
\end{gathered}
$$




$$
I_{i, k} \geq \underline{I}_{i, k}, I_{i, k} \leq \bar{I}_{i, k} \forall i \in \mathscr{I}, k \in \mathscr{N}(i)
$$

In addition to the restrictions mentioned above, there is a set of standard non-negativity constraints relative to consumption and trade flows. I also assume infrastructure symmetry and upper and lower bounds for infrastructure investments in equations 2.11 and 2.13. The strategy to numerically solve this problem depends on some parameters I choose in the calibration. Details on the numerical solution are on Appendix A. 


\section{Data and Calibration}

I calibrate the model to 557 Brazilian microregions ${ }^{1}$, a spatial unit that aggregates economically integrated contiguous cities with similar economic characteristics (IBGE, 2002). The microregions have been widely used in studies with Brazilian data as a good approximation of the concepts of local labor market and the U.S.'s Commuting Zones - see Dix-Carneiro and Kovak (2017) and Dix-Carneiro, Soares and Ulyssea (2018). Based on this economically meaningful geographical unit, I represent the Brazilian road network as a connected graph in which each microregion represents a node and each region is connected with its contiguous ones.

I use the Brazilian Demographic Census for 2010 to obtain population at the microregion level $-L_{i}$. I also aggregate the municipalities' GDP for 2010 (IBGE, 2017) in order to have an estimate for the microregions' production levels, so $Y_{i}^{n}=G D P_{i}$. As in Fajgelbaum and Schaal (2017), I set the curvature of the utility function with $\alpha=0.4$ and the elasticity of substitution between goods $\sigma=5$. This elasticity has a direct relationship with the elasticity of trade and the gravity equation in a wide class of trade models (HEAD; MAYER, 2014).

The log-linear transport technology in equation 2.4 elucidates that infrastructure improvements are associated with lower trade costs ${ }^{2}$. The elasticities of trade costs relative to the infrastructure investment and trade flows $-\gamma$ and $\beta$ - are calibrated based on Couture, Duranton and Turner (2018) results, as in Fajgelbaum and Schaal (2017). I assume $\gamma=0.10$ and $\beta=0.13$, which implies congestion dominance and decreasing returns to scale.

Following Graff (2019), I use the average speed between two connected regions as a proxy for infrastructure quality and use data on speeds and distances between the population centroids of each region from OpenStreetMap, an open source routing service ${ }^{3}$. The mean observed average speed is $49 \mathrm{~km} / \mathrm{h}$ with standard

1 I exclude the Fernando de Noronha microregion since it is an isolated island.

2 Assuming positive returns to investments, i.e. $\gamma>0$.

3 The API is not able to find routes for two remote areas in the Brazilian Amazon. In these 
deviation of $15 \mathrm{~km} / \mathrm{h}$.

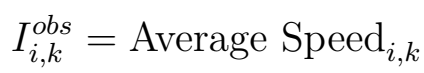

I calibrate the geographic trade costs based on Atkin and Donaldson (2015), which use detailed retail data on goods identified at the barcode-level and find that intra-national trade costs have a strong positive relationship with distance between origin and destination in logarithmic scale. I use their preferred specification for the U.S. that implies:

$$
\delta_{i, k}^{\tau}=0.0106 \times \ln \left(\text { Dist }_{i, k}\right)
$$

The investment cost at each edge is calculated based on Collier, Kirchberger and Söderbom (2016) estimates, as in Fajgelbaum and Schaal (2017). Using a large sample of low and middle income countries' road infrastructure projects from the World Bank, Collier, Kirchberger and Söderbom (2016) estimates imply that the unit cost of the investment follows this relationship:

$$
\ln \left(\delta_{i, k}^{I}\right)=\delta^{I}-0.11 \times 1_{\text {Dist }_{i, k}>50 k m}+0.12 \times \ln \left(\mid \Delta \text { elev }_{i, k} \mid\right)+\ln \left(\text { Dist }_{i, k}\right)
$$

Equation 3.3 states that the cost of infrastructure is increasing in distance but not in a continuous way due to the index function related to projects longer than $50 \mathrm{~km}$. Furthermore, there is also a positive relationship between the cost and how rough the terrain is. At this point, I proceed slightly differently from Collier, Kirchberger and Söderbom (2016). Instead of using the ruggedness index as defined in Nunn and Puga (2012), I use the absolute value of the difference of the population-weighted average elevations between two locations. The variables are measured in the same unit and have pretty similar meanings. Finally, $\delta_{I}$ is a scaling parameter that I calibrate to ensure that equation 2.6 holds under $I_{i, k}=I_{i, k}^{o b s}$ and $K=1$.

cases, I consider the walking speed of $4 \mathrm{~km} / \mathrm{h}$ and the euclidean distance between these regions and their connected ones. 
To create incentives for trade, I consider $N=4$ sectors based on the Brazilian urban hierarchy. I use the Região de Influência das Cidades - REGIC (IBGE, 2007), major research conducted by IBGE that classify the Brazilian urban network based on several variables such as trade, services, transportation and health. REGIC uses the interdependence between the cities in order to identify their importance in the urban network. Since I use a larger spatial unit, I assign the role in the urban hierarchy for each region as the same as the greater level of the cities within it. This hypothesis is based on the definition of microregion explained earlier, since it aggregates contiguous cities with similar economic characteristics. Table 1 shows the REGIC's codes for each tier and the number of regions resulted from this aggregation. More details can be found in Appendix B.

Table 1 - Regions and sectors

\begin{tabular}{ccc}
\hline \hline & REGIC & \# of regions \\
\hline Tier 1 & 1A, 1B, 1C & 12 \\
Tier 2 & 2A, 2B, 2C & 69 \\
Tier 3 & 3A, 3B, 3C & 151 \\
Tier 4 & 4A, 4B, 4C, 5 & 325 \\
\hline \hline
\end{tabular}

Notes: This table shows the corresponding REGIC's codes and the number of producing microregions for each good/hierarchy level.

Note that the higher level in the hierarchy the more spatially scarce the corresponding good become. This feature accounts for spatial concentration of specific goods and, consequently, implies a kind of advantage to those regions in the higher levels of the urban hierarchy in the trade network.

My approach contrasts with the previous works that use similar versions of this model. Fajgelbaum and Schaal (2017) assume that each of the ten most populated regions produces a differentiated good and all others produce a homogeneous good. Graff (2019)'s calibration strategy is based on two different goods: an urban and a rural one and the definition also relies solely on population criteria ${ }^{4}$. My

4 Graff (2019) uses a iterative process to classify a region as urban or rural and guarantee that the share of population living in urban areas equals of actual data. 
approach falls in between these two since it overcomes the urban-rural dichotomy of Graff (2019)'s paper, allowing for more sectors, and soften the strict dependence on great regions in Fajgelbaum and Schaal (2017), introducing goods differentiated by hierarchy level rather than by an ordered population rank. 


\section{Gains from Optimal Reallocation}

I conduct two simulations. In the first one, I solve the planner's problem holding the infrastructure network fixed, $I_{i, k}=I_{i, k}^{o b s}$, which means that the planner chooses the optimal allocations of consumption and trade flows given the current road network. I use these results as the baseline allocation of the economy. I then solve the full planner's problem as stated in the previous section. I set the total amount of infrastructure as fixed $(K=1)$ and impose the the walking speed as lower bound $\underline{I}_{i, k}=4$ and a reasonable upper limit for road speed, $\bar{I}_{i, k}=120$, as the upper bound for the network's edges. In this exercise, the planner can reshuffle roads within the country to improve the connection between some locations at the expense of others in order to maximize aggregate welfare.

The calibration procedure discussed in the previous section requires a first step before the counterfactual simulation. Starting from the Brazilian road network I create a discretized one that represents the infrastructure connections between the Brazilian microregions. Every comparison between the baseline and optimal allocations depends on this network. Figures 1 and 2 show the actual and the discretized Brazilian road networks, respectively.

Figure 1 shows the main roads in the Brazilian road network. Note that there is a significant concentration of roads near the coast and in the southernmost regions. It reflects the overall population distribution and the spatial concentration of wealth in the Brazilian territory. This becomes clearer in Figure 2, which shows the discretized network and microregions' weighted-population centroids. The southernmost regions are more populous ones and have better road infrastructure - depicted by the edges' width in the graph - compared to more geographically remote areas in the Brazilian Amazon and the northeast regions. 
Figure 1 - Brazilian road network

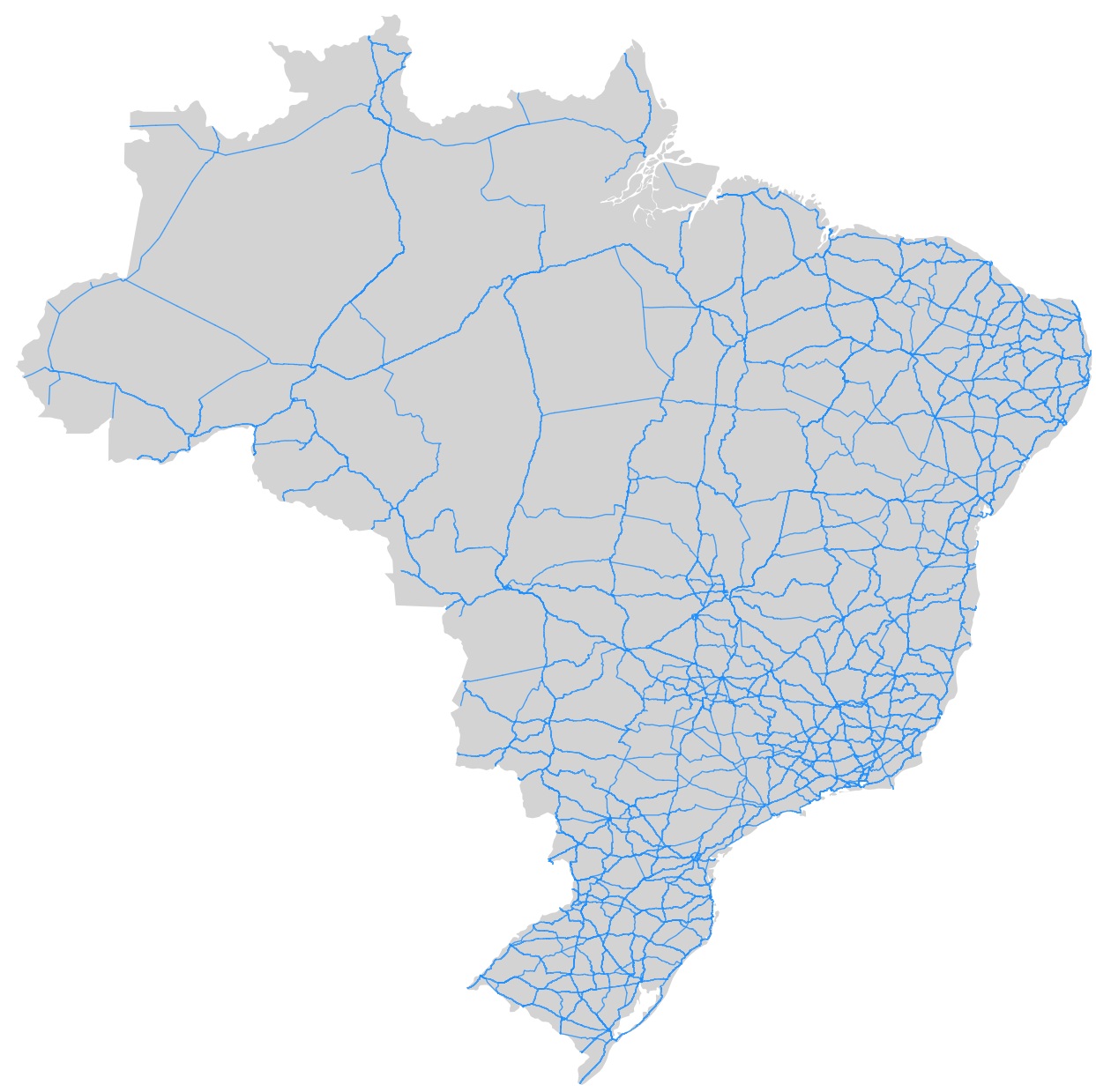

Notes: This figure shows the Brazilian road network based on data from Departamento Nacional de Infraestrutura de Transportes - DNIT. 
Figure 2 - Discretized network

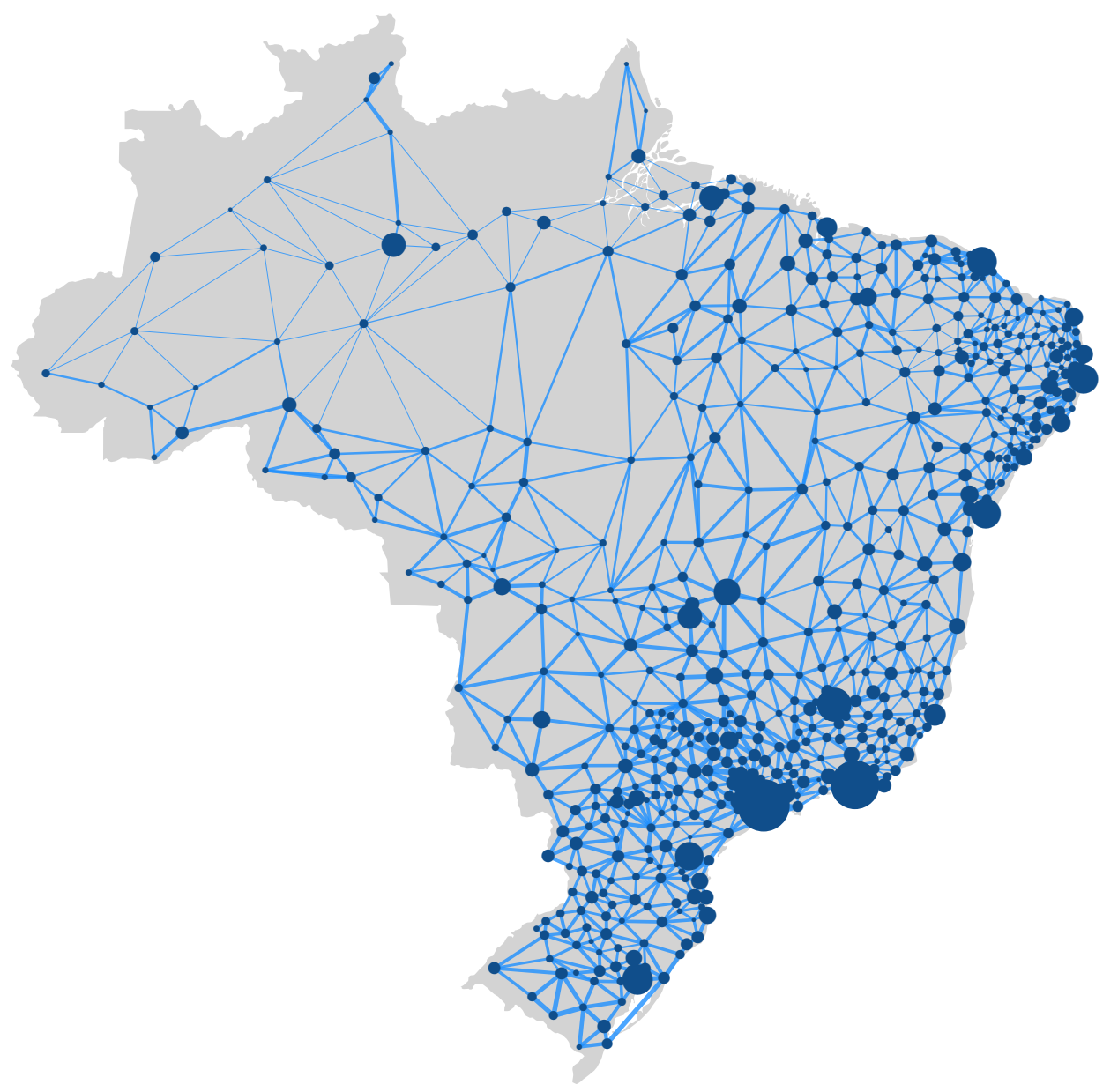

Notes: This figure shows the discretized network. The nodes' size depict the population of each microregion and the edges' width show the level of infrastructure between each connected node. 
Figure 3 shows the results of the hypothetical optimal reshuffling of roads. As in the discretized graph in Figure 2, the edges' widths represent the infrastructure quality, i.e. speed. The color of the weighted-population centroids illustrates the

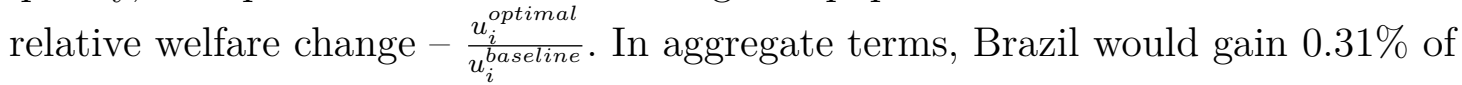
welfare if better organize its road network for intranational trade. The magnitude is in line with Graff (2019)'s results for countries in similar development stages. The more interesting results, however, refers to the spatial variations in infrastructure allocation and welfare.

There are three main patterns in the resulting allocation of roads. The first one is the market integration effects of infrastructure reallocation for the regions nearby the coast and the middle of Brazil. There is a significant increase in the amount of infrastructure allocated to connect the center of Brazil with regions further north and northeast. The second main pattern is the increase in infrastructure facilitating trade with the most populated areas. This reflects the interdependence of the smaller regions relative to those more densely populated and urbanized regions, as described by the hierarchy property of trade. The last one refers to the remote areas in the Brazilian Amazon. Note that despite the increase in the connection with some states' capitals, the far west regions remain with poor transport infrastructure regarding connections with the wealthy east coast. 
Figure 3 - Optimal road network

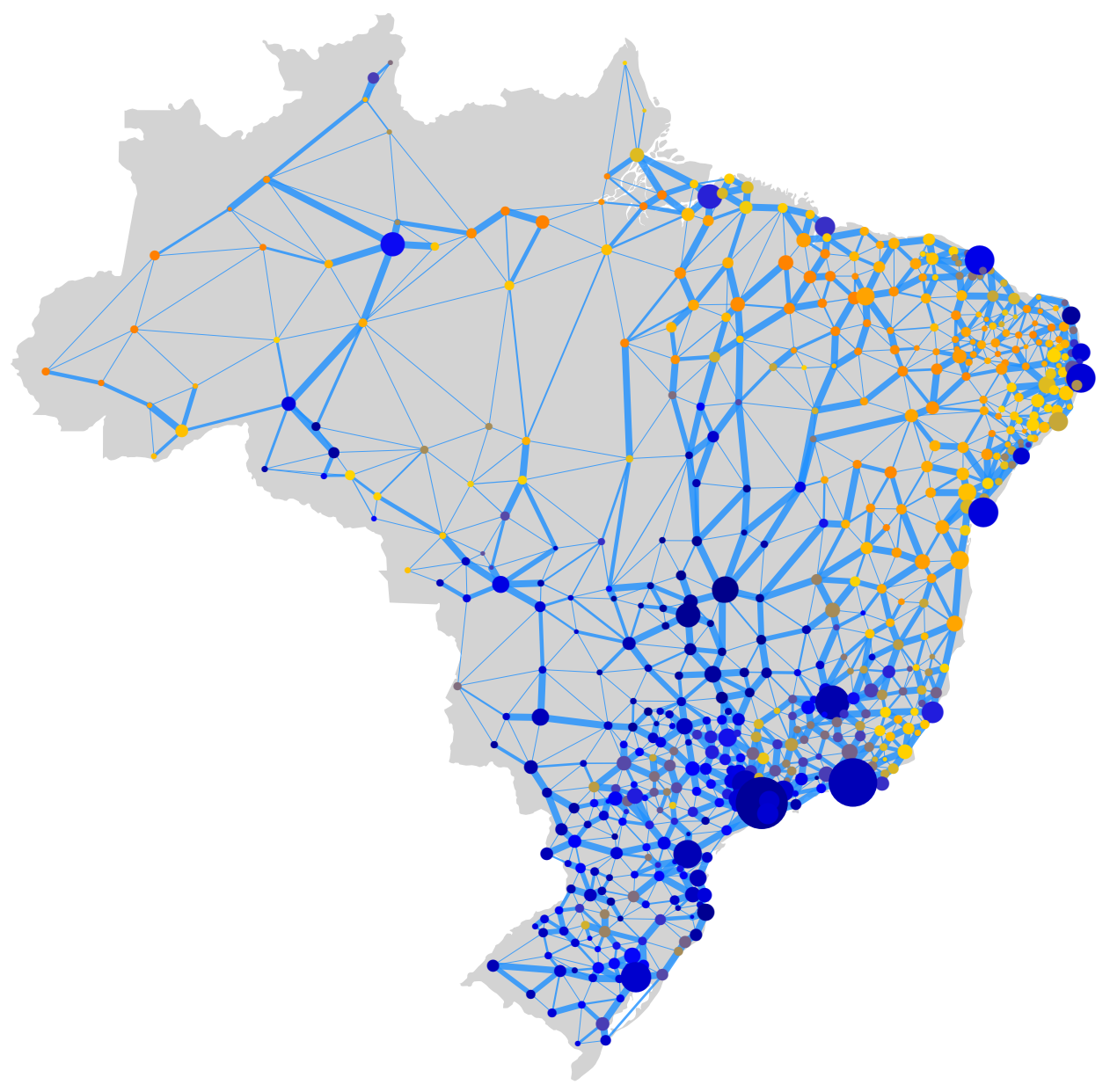

Notes: This figure shows the optimized network. The nodes' size depict the population of each microregion and the edges' width show the level of infrastructure between each connected node. The nodes' color represent the welfare gain. The more yellow, the greater the relative welfare gain compared to the baseline allocation. 
As welfare changes are positively correlated with changes in the infrastructure $^{1}$ - see Figure 4 - and given the different aspects of road reallocation within the Brazilian territory, there is also a major spatial variation in welfare changes, as Figure 3 already suggests. Figures 5 and 6 display the welfare gains from the optimal reallocation of roads in two levels of aggregation.

Figure 4 - Welfare and Infrastructure changes

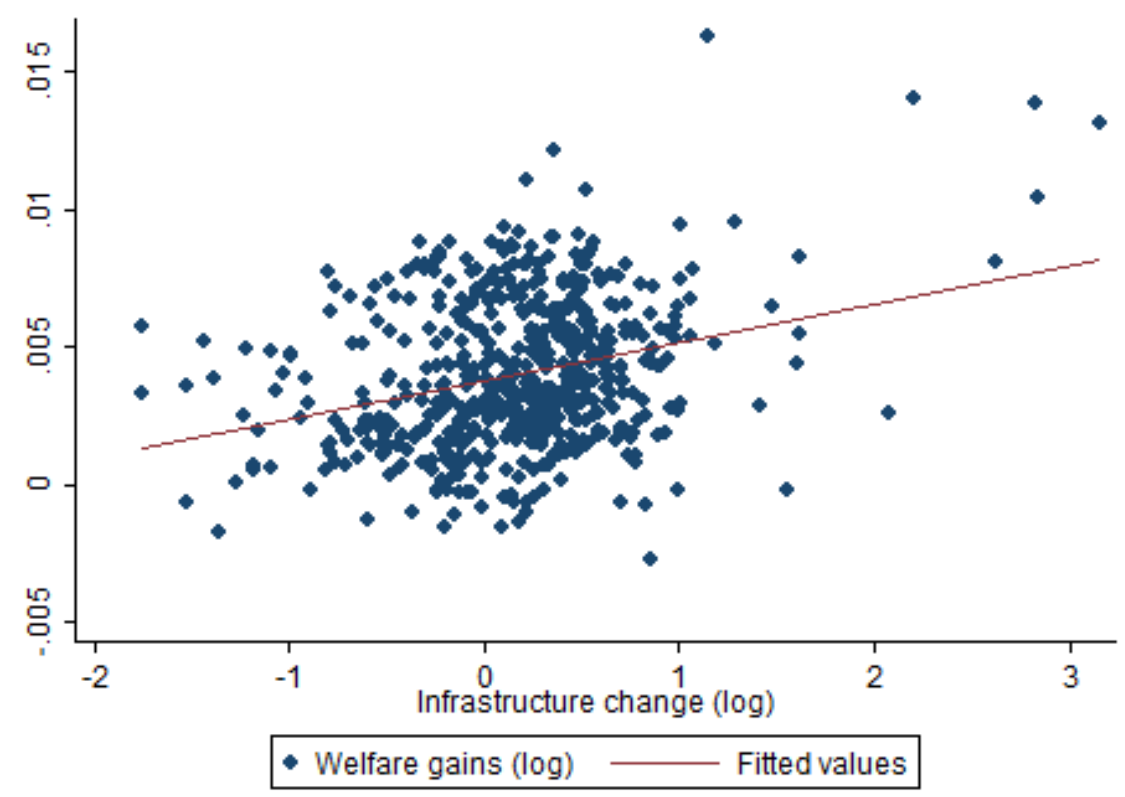

Notes: This figure plots the relative welfare gains from optimal reallocation and the relative changes in transport infrastructure for the microregions. Relative welfare gain and the infrastructure change for a given microregion $i$ are measured as $\log \left(u_{i}^{\text {optimal }} / u_{i}^{\text {baseline }}\right)$ and $\log \left(\sum_{k \in N(i)} I_{i, k}^{o p t} / \sum_{k \in N(i)} I_{i, k}^{\text {obs }}\right)$, respectively.

Figure 5 depicts the welfare changes at the microregion level, as defined in Figure 3. The gains range from $-0.27 \%$ to $1.64 \%$ and the median microregion gains $0.36 \%$ of welfare. The distribution of welfare gains follows approximately a normal distribution with equivalent mean $(0.40 \%)$ and standard deviation $(0.27 \%)^{2}$, and

1 I use the sum of all connecting edges to compute the infrastructure for each node in the graph. Formally, the infrastructure for a given node $i$ is $\sum_{k \in N(i)} I_{i, k}$.

2 See Appendix C. 
roughly $90 \%$ of the microregions experience increases in welfare. Figure 5 highlights that the most benefited regions are located in Brazil's north and northeast. Also, note that the very center of the country contains the majority of the less benefited regions. The wealthier part of the country, the southernmost regions along the coast, present very heterogeneous impact within its microregions.

I then aggregate welfare at the state level and calculate its relative variation

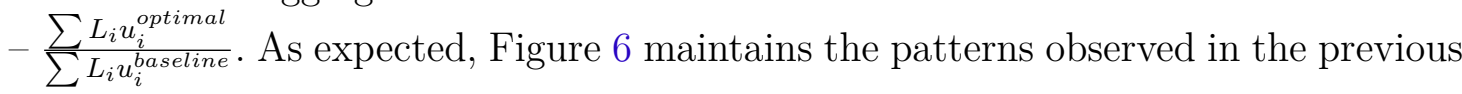
one. The remote states in north Brazil together with some states in the northeast region are the ones who benefit the most from the optimal reallocation. Despite significantly heterogeneous at the microregion level, the welfare gains for the Brazilian southernmost states are very modest, when positive. 
Figure 5 - Spatial distribution of welfare gains - microregions
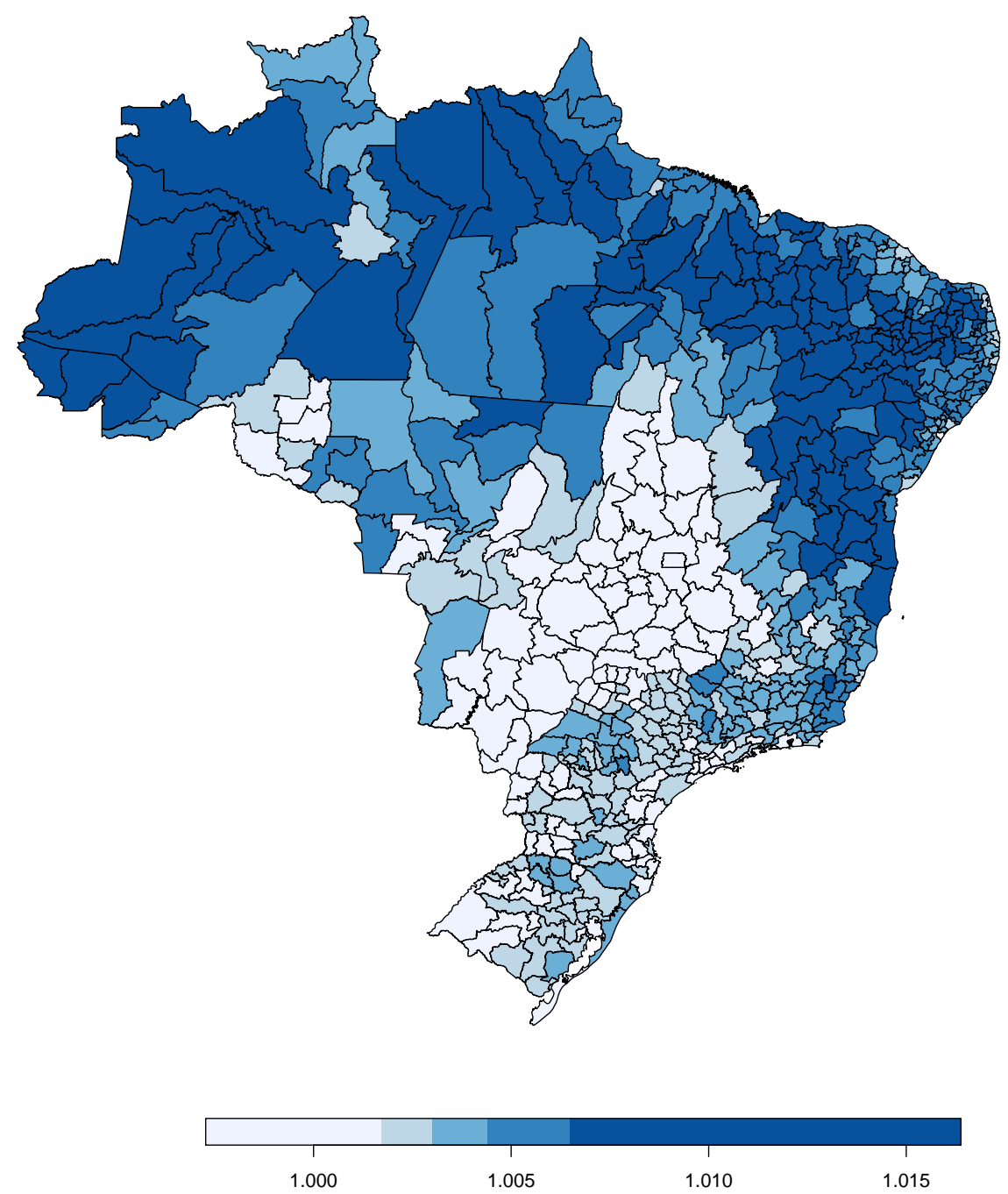

Notes: This figure shows the relative welfare gain from optimal reallocation at the microregion level. Welfare gain is measured as $u_{i}^{\text {optimal }} / u_{i}^{\text {baseline }}$. 
Figure 6 - Spatial distribution of welfare gains - states
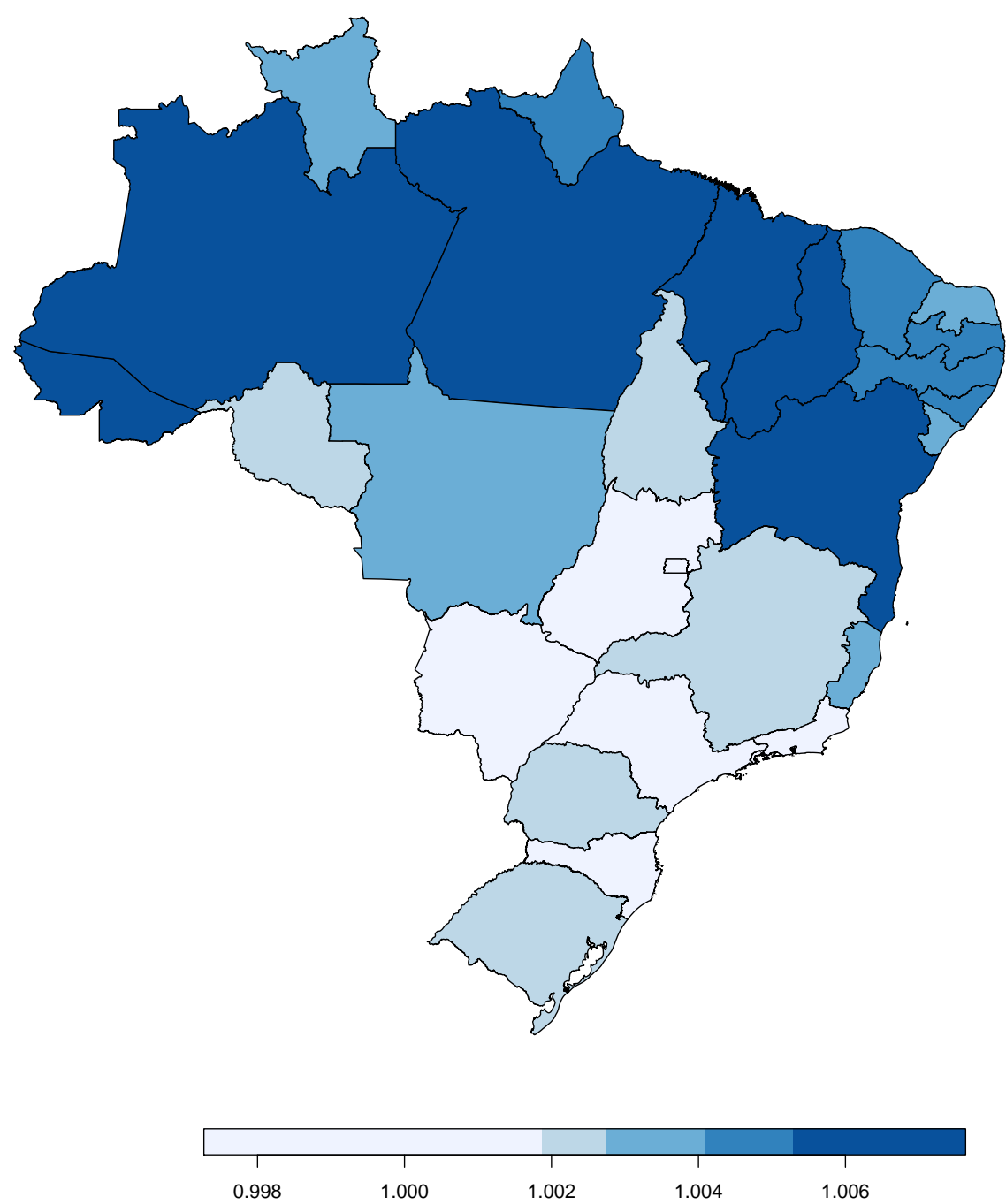

Notes: This figure shows the relative welfare gain from optimal reallocation at the state level. Welfare gain for a given state $S$ is measured as $\sum_{i \in S} u_{i}^{\text {optimal }} L_{i} / \sum_{i \in S} u_{i}^{\text {baseline }} L_{i}$. 
Finally, these results suggest a significant reallocation of infrastructure from the most rich and populous regions to the poorer and more remote ones, with large spatial heterogeneity at the microregion level. As Graff (2019), I argue that the resulting welfare changes reveal the relative supply of transport infrastructure within the trade network. Regions with higher (lower) welfare gains are relatively under(over)supplied of transport infrastructure. So the spatial variation in the welfare gains reflects the spatial misallocation of roads within Brazil. The next section explores one of the factors that can explain this pattern of spatial misallocation. 


\section{Brasília and the Spatial Misallocation of Roads}

Brazil has a large dependence on highways for transportation of both passengers and freight throughout the country. In 2011, the cargo transported by roads represented more than $60 \%$ of the total (BIRD; STRAUB, 2020). If we consider only intranational trade flows, this dependency can be even stronger. The national highway system, however, is relatively recent and its development was largely boosted by public investments. The history of the Brazilian road network can be briefly summarized in two main phases.

Until the 1950s, roads were restricted to the coastal regions in Brazil's south and southeast, the richer and more populated regions in the country. Between 1955 and 1960, however, a large historical event changed the Brazilian landscape and paved the way to a national highway system: the creation of the new federal capital city, Brasília. Together with the planned city, the government constructed eight highways in order to connect Brasília with the rest of the country in a large infrastructure project. The so-called Radial Highways fostered the creation of the national highway system. According to Bird and Straub (2020), the road length grew about $471 \%$ in the second half of the last century. Besides that, the pattern of the expansion after the Radial Highways was towards connecting the main hinterland urban centers, such as Belém and Belo Horizonte, to Brasília (World Bank, 2008). There were quantitative and qualitative changes in the road expansion since the early 1960s, when Brasília and the highways were completed.

I ask whether the Brasília and its Radial Highways creations influenced the current (in)efficiency of the Brazilian transport network. I use the relative welfare gain from optimal reallocation of roads as the variable of interest and explore plausibly exogenous variation in road allocation to provide reduced-form evidence on the effects of this large infrastructure project on the transport network (in)efficiency almost 60 years later. 
There are many channels through which the Radial Highways can affect the welfare gains, my measure of relative misallocation of roads. I do not explore these channels but rather provide their net effect, which can be ambiguous. On the one hand, the roads boosted the development of the connected regions in multiple dimensions such as agricultural productivity (ASTORGA, 2019), trade and migration flows (MORTEN; OLIVEIRA, 2016) and GDP growth (BIRD; STRAUB, 2020). If this big push was sufficiently large, the connected regions are currently important hubs in the trade network and strengthening their connections and welfare could be efficient from the social planner's view. On the other hand, however, the highways also connected some remote and almost unpopulated regions, which are currently small regions and with virtually no importance in the Brazilian trade network. The infrastructure wasted in these oversupplied regions could be better allocated in the under-supplied ones and increase their consumption levels may be welfare improving at the national level.

The main challenge in estimating the causal effects of the highways is the endogeneity of route choice. If the highways' project was designed to connect regions with higher propensity to trade with each other or, contrary, to promote trade between non-trading regions, the OLS estimates will be biased. To address this issue, I follow Morten and Oliveira (2016) and create the predicted highway network that would have been built if the government had minimized the highways' building cost while integrating the country. As Morten and Oliveira (2016) argue, the goal of highway system was to connect the new federal capital to all other state capitals in eight directions. Therefore, I divide the state capitals in eight corresponding segments: north, northeast, east, southeast, south, southwest, west and northwest, and compute the least-cost path to connect all state capitals within each direction, minimizing the euclidean distance. Figure 7 depicts the Radial Highways and the resulting Euclidean Minimum Spanning Tree (EMST). 
Figure 7 - Radial Highways and Euclidean Minimum Spanning Tree

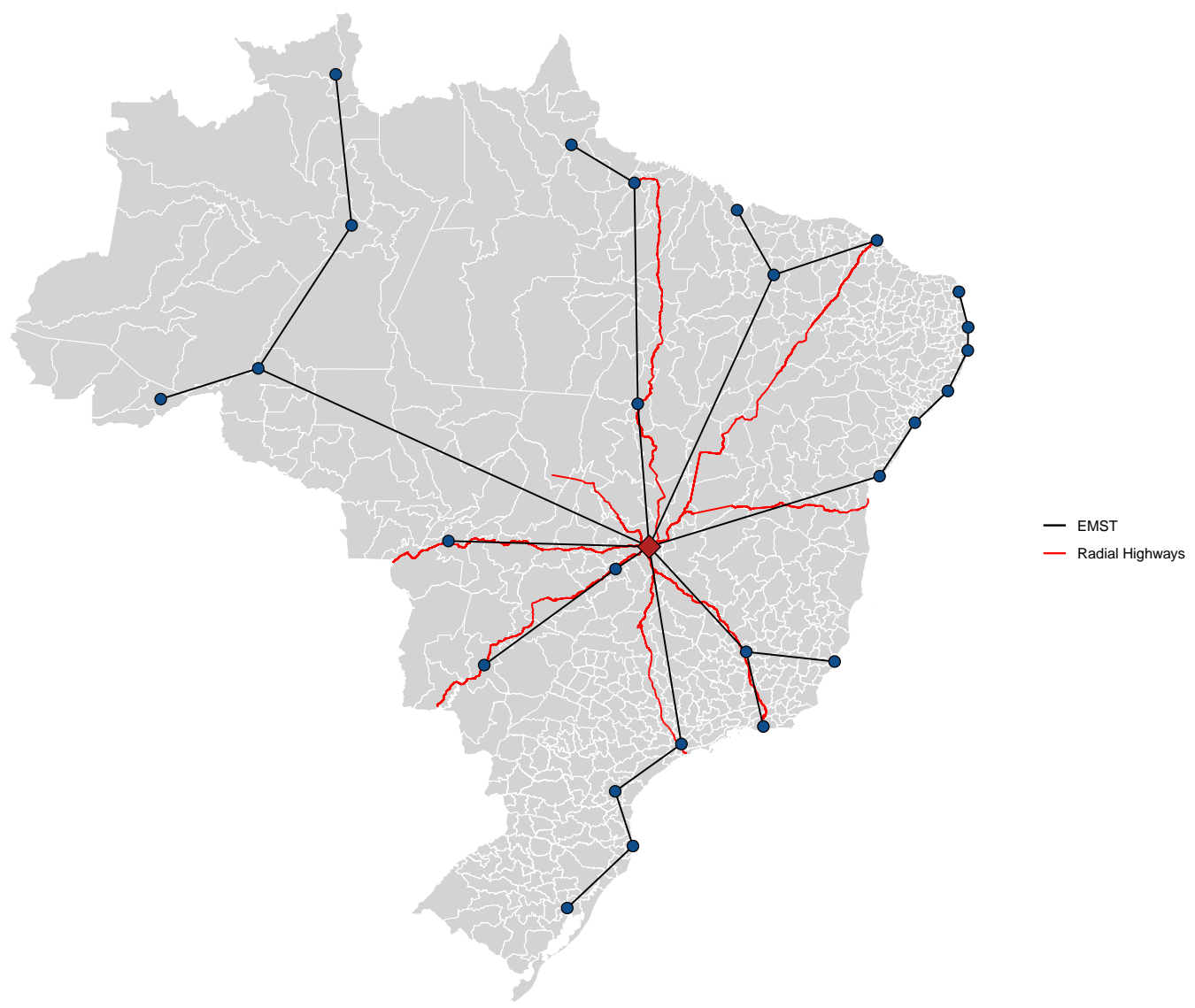

Notes: This figure shows the Brasília's Radial Highways (red lines) and the Euclidean Minimum Spanning Tree (black lines) crossing the microregions boundaries. Radial Highways data are from Departamento Nacional de Infraestrutura de Transportes-DNIT and the Euclidean Minimum Spanning Tree is calculated based on Morten and Oliveira (2016). Brasília is the red diamond in the middle of Brazil and the states' capital cities are the black dots. 
As in Morten and Oliveira (2016) and Astorga (2019), I use the EMST network as an instrumental variable for the Radial Highways. Table 2 shows the results of the reduced-form estimates looking at the extensive margin of the Radial Highways, i.e., whether the highways intersect a given microregion. In this case, the instrumental variable is also a binary variable indicating intersection, but regarding the EMST. I multiply the relative welfare gains by 100 to make the coefficients readable.

In column $1 \mathrm{I}$ show the OLS estimate, which is negative and statistically significant. Column 2 shows the instrumental variables estimation and suggest that the OLS coefficient is upward biased. In column 3 I remove all the microregions that contain a state capital since they were endogenously chosen to be the highways' terminal points. I add state fixed effects in column 4 in order to control for any state specific characteristic, especially concerning the recent infrastructure plans at the state level carried out by local governments ${ }^{1}$. Columns 5 and 6 add hierarchy - i.e. sector - fixed effects and a set of controls such as GDP, population and latitude - which I use in the counterfactual simulations -, respectively. All coefficients are negative and significant under standard significance levels. My preferred specification, column 6 , implies that microregions intersected by the Radial Highways have, on average, less 0.51p.p. of welfare gain compared to those not intersected by the highways. These regions are relatively oversupplied of transport infrastructure.

1 Some important states such as Minas Gerais and Pará implemented local level infrastructure plans, called Plano Estadual de Logísitca e Transportes - PELT. 
Table 2 - Effects of the Radial Highways: extensive margin

\begin{tabular}{lcccccc}
\hline \hline & \multicolumn{7}{c}{ Welfare Gains from Optimal Reallocation } \\
\cline { 2 - 7 } & $(1)$ & $(2)$ & $(3)$ & $(4)$ & $(5)$ & $(6)$ \\
& OLS & IV & IV & IV & IV & IV \\
& & & & & & \\
\hline Radial & -0.15 & -0.46 & -0.36 & -0.55 & -0.51 & -0.51 \\
& $(0.03)$ & $(0.12)$ & $(0.13)$ & $(0.21)$ & $(0.20)$ & $(0.21)$ \\
Capitals removed & No & No & Yes & Yes & Yes & Yes \\
State fixed effects & No & No & No & Yes & Yes & Yes \\
Hierarchy fixed effects & No & No & No & No & Yes & Yes \\
Controls & No & No & No & No & No & Yes \\
Observations & & & & & & \\
\hline \hline
\end{tabular}

Notes: This table shows the results using a dummy variable indicating intersection to the Radial Highways. Column (1) reports the OLS estimation, and columns (2) to (6) shows the IV estimates using a dummy indicating intersection to the EMST as the instrumental variable. Column (3) excludes the microregions that contain a state capital city. Column (4) adds state fixed effects. Column (5) includes good fixed effects. Column (6) adds a set of controls variables used in the counterfactual simulation such as GDP, population and latitude. Robust standard errors in parentheses.

The results in Table 2 mean that despite the already documented positive effects of the Brasília Radial Highways, it also caused a significant waste of infrastructure by inefficiently allocating it to less important regions in the Brazilian internal trade network. Note that if the causal mechanism driving the negative effects on welfare in Table 2 are related to the misallocation of road infrastructure, one should expect pretty similar evidence when looking at the intensive margin of the infrastructure investments. Thus, the results should be maintained qualitatively when I use the intensity of the treatment as independent variable.

Table 3 shows the results using the roads' length as the explanatory variables. I use the lengths of the Radial Highways and the EMST in kilometers as the variable of interest and instrumental variable, respectively. Both variables are measured in 
$\log$ scale $^{2}$. The columns follow the same structure of the last table and the results present the very same pattern of those in Table 2: the OLS' coefficient is upward biased and all the IV's coefficients are negative and statistically significant. These results show that the greater the length of the highways within a given microregion, the lower the relative welfare gain from the optimal reshuffling of roads. Besides being consistent with the ones in Table 2, these results confirms the argument that the amount of misallocated infrastructure in the 1960s do influence the current internal trade network through trade costs.

Table 3 - Effects of the Radial Highways: intensive margin

\begin{tabular}{lcccccc}
\hline \hline & \multicolumn{7}{c}{ Welfare Gains from Optimal Reallocation } \\
\cline { 2 - 7 } & OLS & IV & IV & IV & IV & IV \\
& & & & & & \\
\hline Radial Length (log) & -0.03 & -0.09 & -0.07 & -0.13 & -0.12 & -0.12 \\
& $(0.01)$ & $(0.02)$ & $(0.03)$ & $(0.05)$ & $(0.05)$ & $(0.05)$ \\
Capitals removed & No & No & Yes & Yes & Yes & Yes \\
State fixed effects & No & No & No & Yes & Yes & Yes \\
Hierarchy fixed effects & No & No & No & No & Yes & Yes \\
Controls & No & No & No & No & No & Yes \\
Observations & & & & & & \\
\hline \hline
\end{tabular}

Notes: This table shows the results using the Radial Highways' length in each microregion, in log scale. Column (1) reports the OLS estimation, and columns (2) to (6) shows the IV estimates using the EMST's length in log scale as the instrumental variable. Column (3) excludes the microregions that contain a state capital city. Column (4) adds state fixed effects. Column (5) includes good fixed effects. Column (6) adds a set of controls variables used in the counterfactual simulation such as GDP, population and latitude. Robust standard errors in parentheses.

$\overline{2}$ Actually, they are measured as $\log \left(1+\operatorname{length}_{k m}\right)$. 


\section{Concluding Remarks}

In this paper, I assess the efficiency of the Brazilian transport network focusing on the main transport mode of the country - roads - using a spatial general equilibrium model that encompasses regional trade based on a graph structure. I conduct a hypothetical optimal reshuffling of roads across space that identifies the most inefficient connections of the internal trade network and finds that roads would be reallocated towards the least developed and remote areas in the Brazilian territory, currently relatively under-supplied of transport infrastructure. This exercise would lead to significant aggregate welfare gain - $0.31 \%$ - and large spatial heterogeneity at the subnational level.

I then explore the resulting subnational welfare gains due to the spatial reallocation of infrastructure in reduced-form exercises using a large-scale infrastructure project conducted by the middle of the past century. I use an instrumental variables' framework and find that regions connected by the highways built to integrate Brasília to the rest of the country are currently oversupplied with road infrastructure relative to the non-connected ones. These results are robust to the introduction of a set of fixed effects and controls. They also hold when I use the amount of infrastructure allocated in each region rather than a binary treatment variable.

Together, these results suggest that policymakers should be very cautious when designing major transport infrastructure projects. Despite the widely documented positive effects, which much of the time outweigh their costs, a poorly designed plan can bring important sunk costs regarding opportunity costs. Every bad unit invested can have lasting effects on the trade network. 



\section{Bibliography}

ALMEIDA, E. S. de; HADDAD, E. A.; HEWINGS, G. J. D. Transport-regional equity issue revisited. Regional Studies, Routledge, v. 44, n. 10, p. 1387-1400, 2010. Disponível em: <https://doi.org/10.1080/00343400601056847>.

ANDERSON, J. E.; WINCOOP, E. van. Trade costs. Journal of Economic Literature, American Economic Association, v. 42, n. 3, p. 691-751, aug 2004.

ASTORGA, D. Access to markets and technology adoption in the agricultural sector: Evidence from brazil. Unpublished, 2019.

ASTURIAS, J. Endogenous transportation costs. European Economic Review, Elsevier BV, v. 123, p. 103366, apr 2020.

ATKIN, D.; DONALDSON, D. Who's Getting Globalized? The Size and Implications of Intra-national Trade Costs. [S.l.], 2015. (Working Paper Series, 21439). Disponível em: <http://www.nber.org/papers/w21439>.

BIRD, J.; STRAUB, S. The brasília experiment: The heterogeneous impact of road access on spatial development in brazil. World Development, Elsevier BV, v. 127, p. 104739, mar 2020.

BRANCACCIO, G.; KALOUPTSIDI, M.; PAPAGEORGIOU, T. Geography, transportation, and endogenous trade costs. Econometrica, The Econometric Society, v. 88, n. 2, p. 657-691, 2020.

COLLIER, P.; KIRCHBERGER, M.; SöDERBOM, M. The cost of road infrastructure in low- and middle-income countries. The World Bank Economic Review, Oxford University Press (OUP), v. 30, n. 3, p. 522-548, oct 2016.

COSTINOT, A.; RODRÍGUEZ-CLARE, A. Trade theory with numbers: Quantifying the consequences of globalization. In: Handbook of International Economics. [S.l.]: Elsevier, 2014. p. 197-261.

COUture, V.; DURAnton, G.; TURneR, M. A. Speed. The Review of Economics and Statistics, MIT Press - Journals, v. 100, n. 4, p. 725-739, oct 2018.

DIX-CARNEIRO, R.; KOVAK, B. K. Trade liberalization and regional dynamics. American Economic Review, American Economic Association, v. 107, n. 10, p. 2908-2946, oct 2017. 
DIX-CARNEIRO, R.; SOARES, R. R.; ULYSSEA, G. Economic shocks and crime: Evidence from the brazilian trade liberalization. American Economic Journal: Applied Economics, American Economic Association, v. 10, n. 4, p. 158-195, oct 2018.

FAJGELBAUM, P. D.; SCHAAL, E. Optimal Transport Networks in Spatial Equilibrium. [S.l.], 2017. (Working Paper Series, 23200). Disponível em: $<$ http://www.nber.org/papers/w23200>.

FELBERMAYR, G.; TARASOV, A. Trade and the Spatial Distribution of Transport Infrastructure. [S.1.], 2015. Disponível em: <https://ideas.repec.org/p/ces/ceswps/_5634.html>.

GRAFF, T. Spatial Inefficiencies in Africa's Trade Network. [S.1.], 2019. (Working Paper Series, 25951). Disponível em: <http://www.nber.org/papers/w25951>.

HADDAD, E. A. et al. Assessing the ex ante economic impacts of transportation infrastructure policies in brazil. Journal of Development Effectiveness, Informa UK Limited, v. 3, n. 1, p. 44-61, mar 2011.

HEAD, K.; MAYER, T. Gravity equations: Workhorse,toolkit, and cookbook. In: Handbook of International Economics. [S.l.]: Elsevier, 2014. p. 131-195.

MAGGI, A. J. The gains from international and intranational trade. Unpublished, 2019.

MAGGI, A. J.; HADDAD, E. A. The impact of china's productivity growth on the brazilian economy. Unpublished, 2016.

MORTEn, M.; OLIVEIRA, J. Paving the Way to Development: Costly Migration and Labor Market Integration. [S.1.], 2016. (Working Paper Series, 22158). Disponível em: <http://www.nber.org/papers/w22158>.

NUNN, N.; PUGA, D. Ruggedness: The blessing of bad geography in africa. Review of Economics and Statistics, MIT Press - Journals, v. 94, n. 1, p. 20-36, feb 2012.

SANTAMARIA, M. The gains from reshaping infrastructure: Evidence from the division of germany. Unpublished, 2020. 
Appendix 



\section{APPENDIX A - Hierarchy}

This appendix details some data issues. I use the Brazilian urban hierarchy at the municipality level to create a new one at the microregion level. There are 11 main levels of hierarchy in REGIC, which are shown in Table 4. I aggregate these codes as in Table 1 to create the hierarchy for the Brazilian microregions. Figures 8 and 9 show the maps of the municipality-level and the resulting microregion-level hierarchies.

Table 4 - REGIC's hierarchy levels

\begin{tabular}{lcc}
\hline \hline Code & Hierarchy level & Municipalities \\
\hline 1A & Grande Metrópole Nacional & 1 \\
1B & Metrópole Nacional & 2 \\
1C & Metrópole & 9 \\
2A & Capital Regional A & 11 \\
2B & Capital Regional B & 20 \\
2C & Capital Regional C & 39 \\
3A & Centro Subregional A & 85 \\
3B & Centro Subregional B & 79 \\
4A & Centro de Zona A & 192 \\
4B & Centro de Zona B & 364 \\
5 & Centro Local & 4474 \\
\hline \hline
\end{tabular}

Notes: This table shows the REGIC's hierarchy levels and the number of regions. Data from IBGE (2007). 
Hierarchy - Municipalities
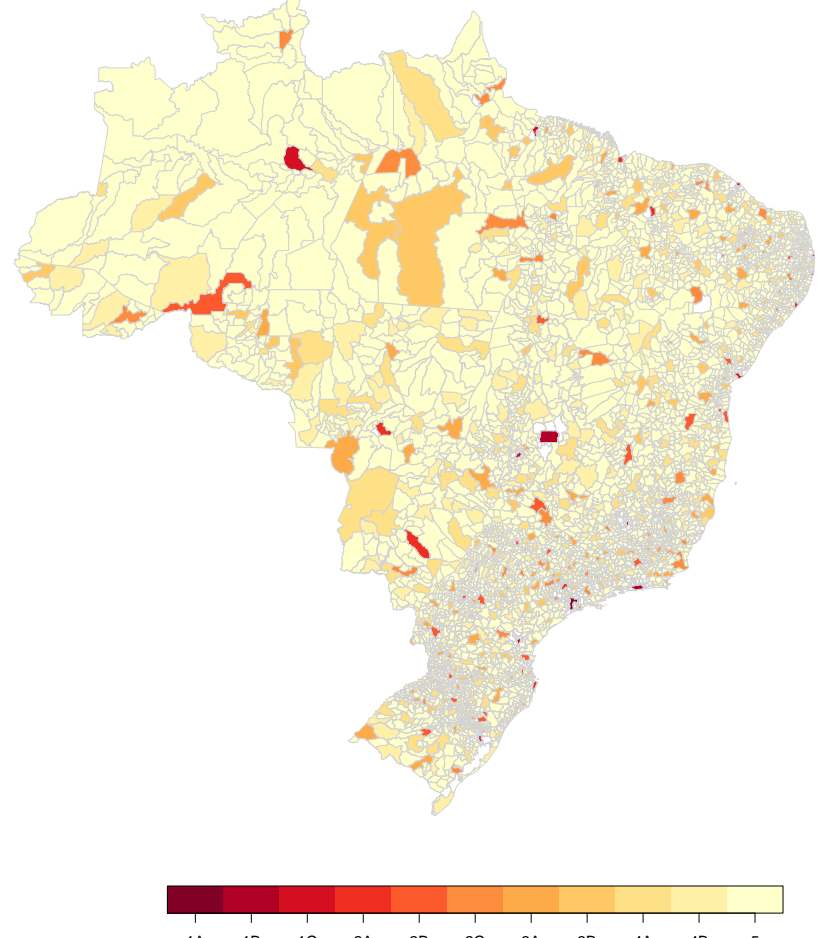

Figure 8 - Hierarchy - Municipalities

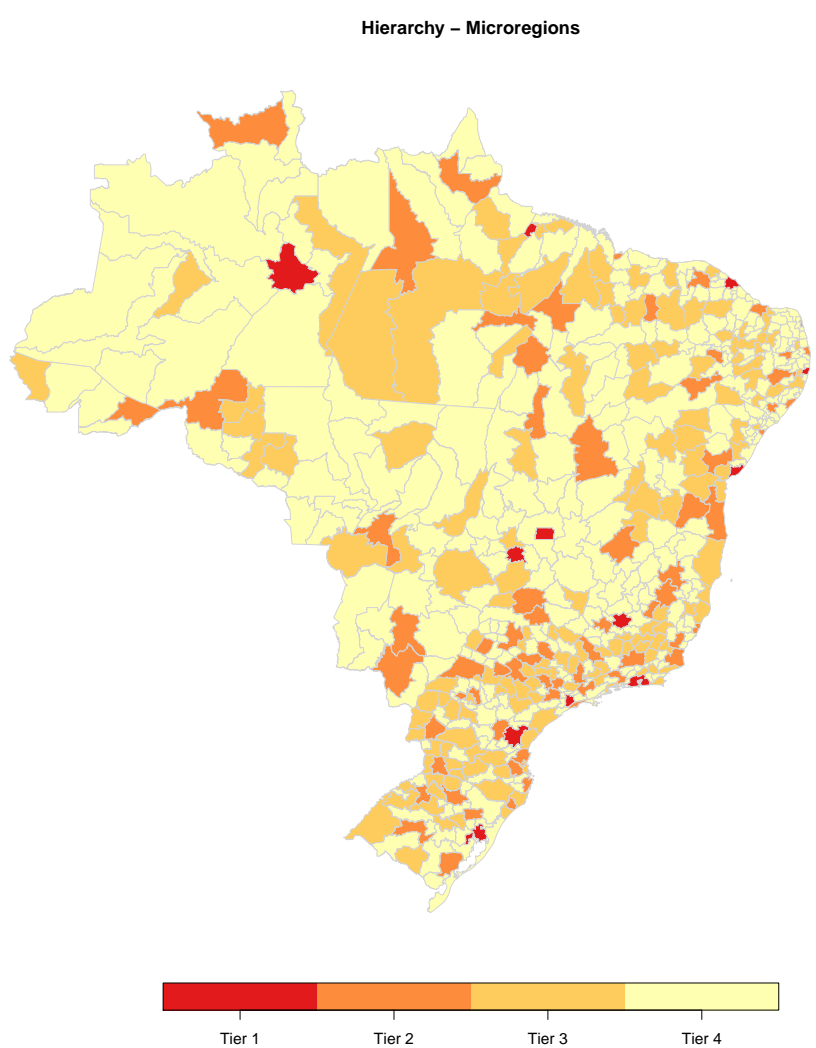

Figure 9 - Hierarchy - Microregions 


\section{APPENDIX B - Numerical Solution}

Once calibrated, the model become a large-scale nonlinear optimization problem since there are 557 microregions, 4 sectors and the main variable of interest in the counterfactual simulation, $I_{i, k}^{o p t}$, is a $557 \times 557$ vector. Fortunately, there are some results from the optimal transport literature that make this large problem numerically tractable. I follow Fajgelbaum and Schaal (2017) and represent the full planner's problem as a nested optimization problem comprehending three sub-problems, namely: the optimal allocations problem, the optimal flows problem and the optimal network problem.

$$
\max _{I_{i, k}} \max _{Q_{i, k}^{n}} \max _{\left\{c_{i}, C_{i}^{n}\right\}} \sum_{i=1}^{I} L_{i} u_{i}\left(c_{i}\right)
$$

As Fajgelbaum and Schaal (2017) show in their Proposition 1, given the transport network $I_{i, k}$, the joint optimal flows and allocation problem is a convex optimization problem assuming fixed labor and convexity of $Q_{i, k}^{n} \tau_{i, k}^{n}$. Since I calibrate $\beta>\gamma$, i.e., there is congestion dominance in trade costs, and the planner's problem consists in maximizing a concave objective function subject to a set of convex constraints.

Under these conditions, the joint optimal flows and allocation problem admits strong duality, which means that the solution of the dual problem coincides with the primal one. The dual problem, however, is computationally more tractable since it reduces the parameters' space and the set of constraints. From the primal 
problem's Lagrangean:

$$
\begin{aligned}
\mathscr{L}= & \sum_{i} L_{i} u\left(c_{i}\right)-\sum_{i} \lambda_{i}^{C}\left[L_{i} c_{i}-\left(\sum_{n=1}^{N}\left(C_{i}^{n}\right)^{\frac{\sigma-1}{\sigma}}\right)^{\frac{\sigma}{\sigma-1}}\right] \\
& -\sum_{i} \sum_{n} \lambda_{i, n}^{P}\left[C_{i}^{n}+\sum_{k \in N(i)} Q_{i, k}^{n}\left(1+\tau_{i, k}^{n}\left(Q_{i, k}^{n}, I_{i, k}\right)\right)-Y_{i}^{n}-\sum_{j \in N(i)} Q_{j, i}^{n}\right] \\
& +\sum_{i} \sum_{k \in N(i)} \sum_{n} \zeta_{i, k, n}^{Q} Q_{i, k}^{n}+\sum_{i} \sum_{n} \zeta_{i, n}^{C} C_{i}^{n}+\sum_{i} \sum_{n} \zeta_{i}^{c} c_{i}
\end{aligned}
$$

Due to complementary slackness, I can write the first-order conditions of the control variables $\left(C_{i}^{n}, Q_{i, k}^{n}, c_{i}\right)$ as functions of the Lagrange Multipliers $\left(\lambda^{P}\right)$ in dimensions $\langle i, n\rangle$ :

$$
\begin{aligned}
c_{i} & =\left(\frac{1}{\alpha}\left(\sum_{n^{\prime}}\left(\lambda_{i, n^{\prime}}^{P}\right)^{1-\sigma}\right)^{\frac{1}{1-\sigma}}\right)^{\frac{1}{\alpha-1}} \\
C_{i}^{n} & =\left[\frac{\lambda_{i, n}^{P}}{\left(\sum_{n^{\prime}}\left(\lambda_{i, n^{\prime}}^{P}\right)^{1-\sigma}\right)^{\frac{1}{1-\sigma}}}\right]^{-\sigma} L_{i} c_{i} \\
Q_{i, k}^{n} & =\left[\frac{1}{1+\beta} \frac{I_{i, k}^{\gamma}}{\delta_{i, k}^{\tau}} \max \left\{\frac{\lambda_{k, n}^{P}}{\lambda_{i, n}^{P}}-1,0\right\}\right]^{\frac{1}{\beta}}
\end{aligned}
$$

Then, I rewrite the Lagrangean as a function of the multipliers $\left(\lambda^{P}\right)$. The dual version of the joint optimal flows and allocation problem is thus:

$$
\min _{\lambda \geq 0} \mathscr{L}(\lambda, x(\lambda))
$$

where $x(\lambda)$ denotes the control variables as functions of the multipliers. With $\lambda$ that solves this minimization problem, the first-order conditions yields the full set of optimal flows and consumption patterns for a given infrastructure network.

As Fajgelbaum and Schaal (2017), I iterate the solution of this problem with the first-order condition of the optimal network problem given the allocations of consumption and trade flows. Assuming infrastructure symmetry as in the original paper, the first-order condition is: 


$$
\begin{gathered}
I_{i, k}^{*}=\left[\frac{\gamma}{\lambda^{I}\left(\delta_{i, k}^{I}+\delta_{k, i}^{I}\right)}\left(\sum_{n} \delta_{i, k}^{\tau} \lambda_{i, n}^{P}\left(Q_{i, k}^{n}\right)^{1+\beta}+\delta_{k, i}^{\tau} \lambda_{k, n}^{P}\left(Q_{k, i}^{n}\right)^{1+\beta}\right)\right]^{\frac{1}{1+\gamma}} \\
I_{i, k}^{o p t}=\min \left[\max \left(I_{i, k}^{*}, \bar{I}_{i, k}\right), \underline{I}_{i, k}\right]
\end{gathered}
$$

where $\lambda^{I}$ is such that the network-building constraint is satisfied for $I_{i, k}^{o p t}$. 



\section{APPENDIX C - Additional Figures}

Figure 10 - Kernel Density: Observed Average Speeds

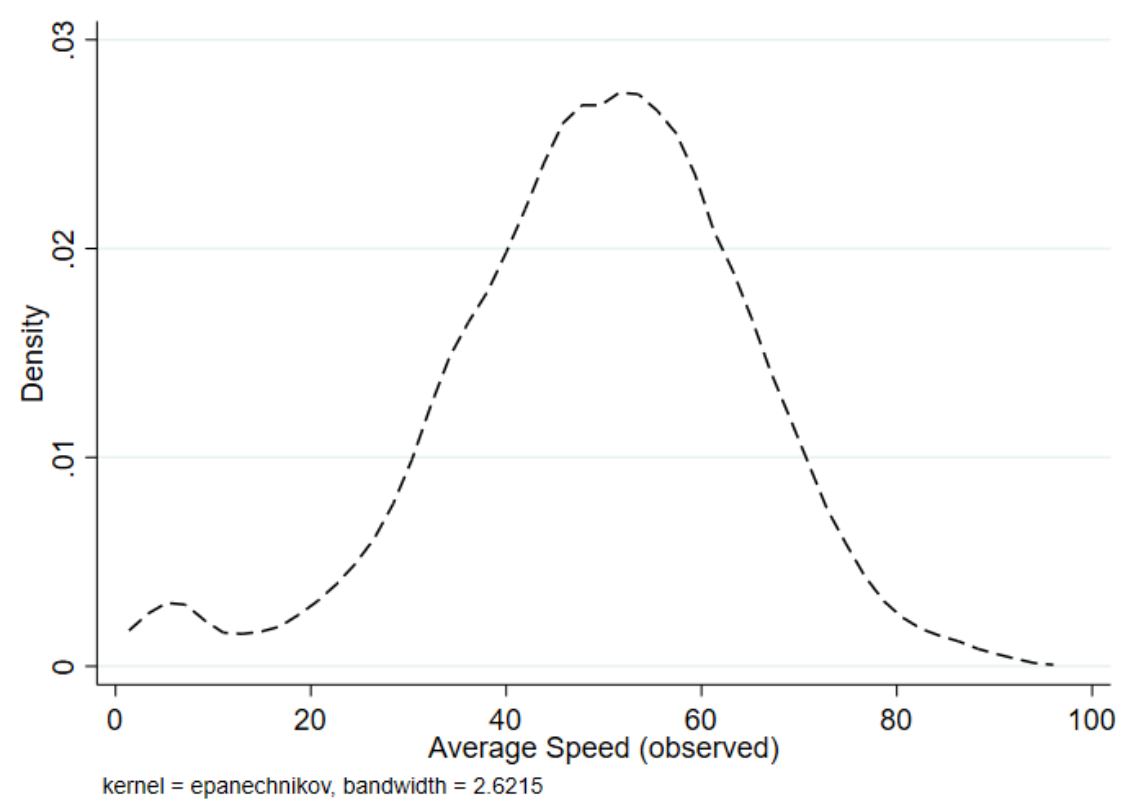


Figure 11 - Histogram: Relative Welfare Gains

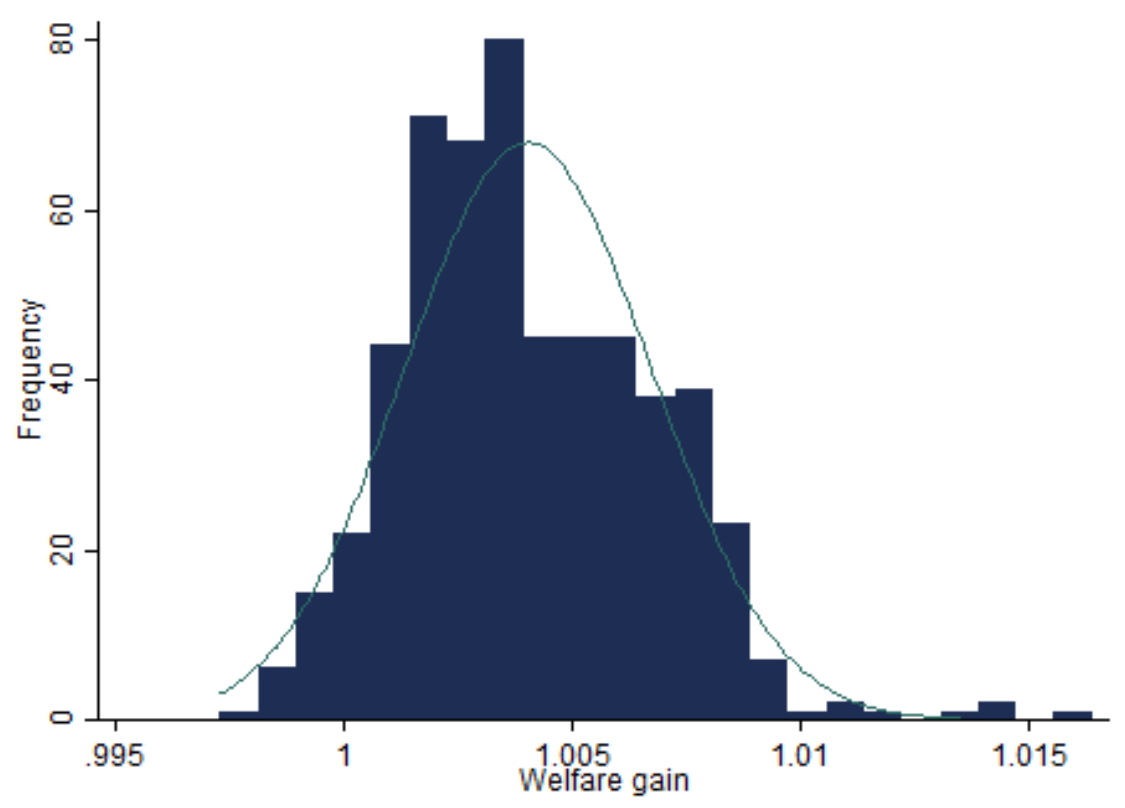

